$03 ; 13 ; 14$

\title{
Управляемая электрическим полем адсорбция микрокапсул при создании планарных структур
}

\author{
() И.В. Маляр, О.И. Гуслякова, Д.М. Митин, С.В. Стецюра
}

Саратовский национальный исследовательский государственный университет им. Н.Г. Чернышевского, Саратов, Россия

E-mail: imalyar@yandex.ru

Поступило в Редакцию 13 сентября 2017 г.

Показано влияние электрического поля, приложенного вдоль поверхности, на адсорбцию положительно заряженных микрокапсул с ядром на стеклянные подложки, приводящее к росту адсорбции микрокапсул вблизи отрицательного контакта до 2 раз по сравнению с адсорбцией вблизи положительного при напряженности поля $1.3 \mathrm{kV} / \mathrm{m}$. Также продемонстрировано, что добавление соли в суспензию при малых концентрациях (до $0.2 \mathrm{M}$ ) снижает этот эффект, однако с ростом концентрации до $0.45 \mathrm{M}$ происходит его усиление до 8 раз.

DOI: 10.21883/PJTF.2018.04.45633.17039

Основными требованиями к сенсорным структурам, использующим в качестве чувствительного слоя молекулы фермента на поверхности электрохимического преобразователя, являются сохранение биокаталитической активности закрепленных молекул фермента и высокая плотность осаждения молекул фермента на поверхности электрохимического преобразователя, что обеспечивает рост чувствительности к аналиту. В работе [1] было показано, что упаковка фермента в полиэлектролитные контейнеры (капсулы) позволяет максимально сохранить нативное состояние молекул фермента. Полиэлектролитные микрокапсулы - это новый тип объектов, которые могут найти применение во многих областях, в частности в биосенсорике и тераностике [2]. Метод послойной адсорбции позволяет встраивать в их оболочку наночастицы, молекулы-маркеры и другие нанообъекты, что позволяет управлять чувствительностью микрокапсул к среде, их проницаемостью и адсорбционными свойствами. Несмотря на очевидные достоинства полиэлектролитных капсул в качестве контейнеров, 
предохраняющих содержащиеся в них ферменты от неблагоприятных внешних воздействий и в то же время обеспечивающих сохранение их функциональной активности, они имеют и недостатки, такие как трудности манипулирования этими объектами и формирования из них упорядоченных планарных структур [3].

Поскольку микрокапсулы обладают эффективным зарядом в водном растворе и закрепляются на подложке главным образом посредством электростатического взаимодействия, увеличение электрического потенциала поверхности как адсорбента, так и адсорбата должно способствовать иммобилизации микрокапсул [4,5]. Отличительной особенностью микрокапсул, заполненных ферментом, от нанообъектов, описанных в [4,5], является их высокая инерционность, что мешает манипулированию этими объектами и, следовательно, требует создания для этого достаточно высоких напряженностей электрических полей. Часто используемое приложение электрического поля перпендикулярно поверхности подложки [6] может привести к деформации микрокапсулы и частичной потере каталитической активности находящегося в ней фермента. Приложение продольного относительно поверхности подложки электрического поля исключает механическое повреждение капсулы при ее иммобилизации на твердой поверхности, но при этом может увеличить силы взаимодействия между адсорбируемыми объектами и подложкой. Кроме того, создание „тянущего“ поля вдоль границы раздела твердая подложка-полиэлектролит может способствовать созданию градиентного распределения нанообъектов вдоль поверхности подложки [7].

В соответствии с изложенным выше целью настоящей работы было изучение влияния продольного относительно поверхности подложки электрического поля на адсорбцию полиэлектролитных микрокапсул с неудаленным ядром (структура типа ядро-оболочка). Наличие ядра приближало объект по электромеханическим параметрам к капсуле с полезным грузом.

Для экспериментов были синтезированы полиэлектролитные микрокапсулы с ядром $\mathrm{CaCO}_{3}$ аналогично технологии, описанной в [8]. На микронное ядро попеременно проводилась адсорбция полиэлектролитных слоев катионного полиаллиламина гидрохлорида (РАН) и анионного полистиролсульфоната натрия (PSS). Таким образом, на ядре формировались бислои, состоящие из монослоев PAH и PSS. В работе были использованы микрокапсулы, содержащие по три бислоя

Письма в ЖТФ, 2018, том 44, вып. 4 
и дополнительно слой РАН на поверхности, что приводило к наличию эффективного положительного поверхностного заряда. Средний диаметр микрокапсул составлял около $1.4 \pm 0.1 \mu \mathrm{m}$. Для экспериментов были подготовлены водные суспензии микрокапсул с концентрацией $2 \cdot 10^{8} \mathrm{ml}^{-1}$ без добавления и с добавлением $\mathrm{NaCl}$ до концентраций $0.15,0.30$ и $0.45 \mathrm{M}$. Наличие соли в растворе не только может повлиять на результаты адсорбции, но и оказывает значимое влияние на свойства микрокапсул. Например, повышение ионной силы дисперсной среды увеличивает проницаемость полиэлектролитных капсул и может изменить эффективный поверхностный заряд микрокапсулы.

Для экспериментов были использованы подложки, представляющие собой предметное стекло размером $26 \times 15 \mathrm{~mm}$ для оптической микроскопии, которые имеют гладкую поверхность и обеспечивают механическую прочность и изоляционные свойства. На одну из сторон подложек на расстоянии $15 \mathrm{~mm}$ друг от друга через маску напылялись контактные площадки из нержавеющей стали методом магнетронного распыления. Далее подложки кипятились в растворе $\mathrm{NH}_{4} \mathrm{OH}: \mathrm{H}_{2} \mathrm{O}_{2}: \mathrm{H}_{2} \mathrm{O}=1: 1: 4$ (по объему) при температуре $70^{\circ} \mathrm{C}$ в течение $10 \mathrm{~min}$ для удаления органических загрязнений и активизации отрицательно заряженных ОН-групп на поверхности стекла, что необходимо для успешной адсорбции положительно заряженных микрокапсул со слоем РАН на поверхности. После этого подложки промывали в деионизированной воде, сушили и припаивали провода, снова промывали и сушили. Адсорбция микрокапсул проводилась из капли раствора, помещенной в межконтактную область подложки, при приложении постоянного напряжения в диапазоне от 1 до $20 \mathrm{~V}$. После адсорбции образцы промывались и сушились.

Для характеризации полученных образцов был использован сканирующий электронный микроскоп (СЭM) Mira II LMU (Tescan, Чехия). Перед измерением детектором вторичных электронов на образцы наносился нанометровый полупрозрачный слой золота методом ионноплазменного распыления мишени.

На рис. 1 показаны результаты иммобилизации микрокапсул из бессолевой суспензии в зависимости от знака потенциала, подаваемого на электрод. Из рисунка видно, что больше всего микрокапсул адсорбировалось на подложке вблизи отрицательного контакта, а меньше всего - в области положительного. Поскольку визуальный анализ

Письма в ЖТФ, 2018, том 44, вып. 4 

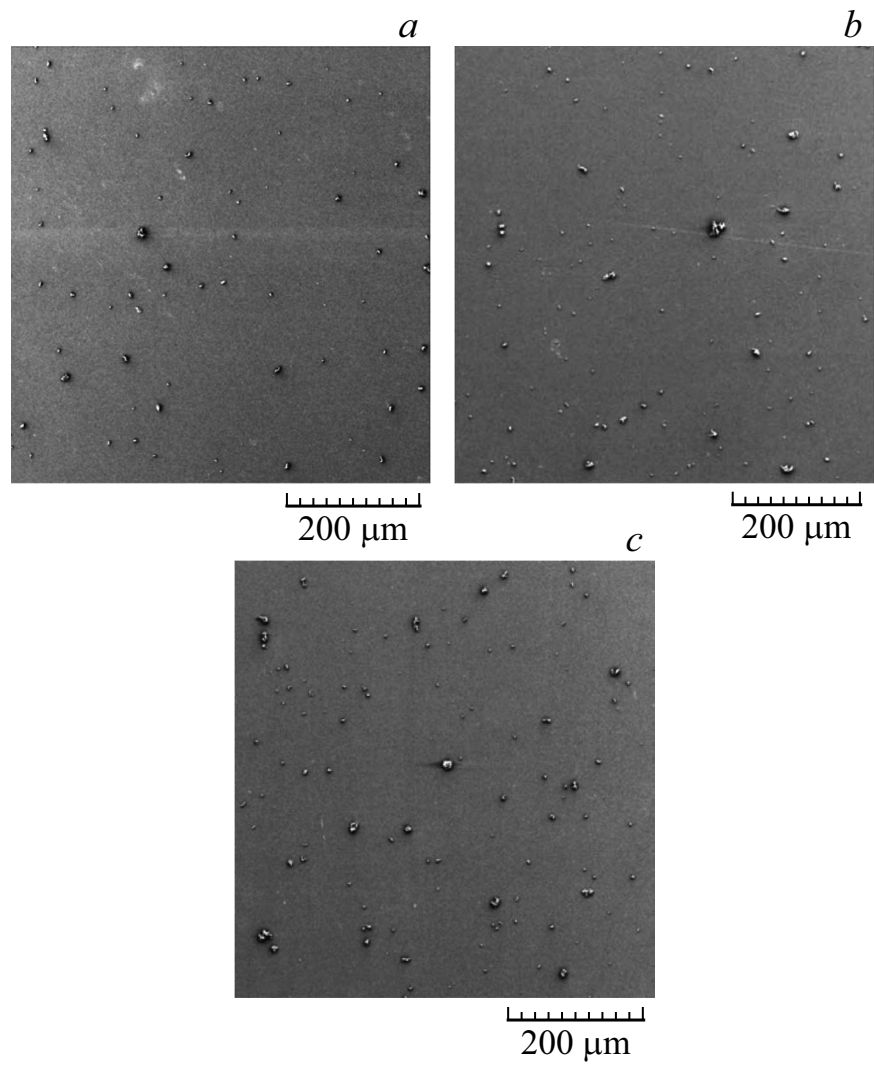

Рис. 1. СЭМ-изображения поверхности подложки с микрокапсулами, адсорбированными без приложения поля $(a)$ и с приложением поля $1.3 \mathrm{kV} / \mathrm{m}$ вблизи положительного $(b)$ и отрицательного $(c)$ контакта.

изображений не дает количественной информации, для оценки степени покрытия поверхности $C$ адсорбированными микрокапсулами и их агрегатами (т.е. процента поверхности, занятой иммобилизованными частицами) полученные СЭМ-изображения были проанализированы в программе Gwyddion. Рассчитанный средний линейный размер иммобилизованных частиц в бессолевом растворе не зависел от напряженности

Письма в ЖТФ, 2018, том 44, вып. 4 
приложенного поля и составил $1.9 \pm 0.1 \mu \mathrm{m}$, что незначительно превышает средний размер микрокапсул и свидетельствует о малой степени агрегации микрокапсул в комплексы. Значения $C$ варьировались от 0.10 до $0.42 \%$ в зависимости от величины и знака потенциала на электроде. Без приложения поля значение $C$ колебалось в пределах $0.20 \pm 0.01 \%$. По полученным значениям были рассчитаны относительное изменение степени покрытия $\Delta_{C}$ при приложении поля, а также коэффициент „селективности“ покрытия $\Delta_{C}^{ \pm}$как относительное изменение поверхностной плотности микрокапсул на поверхности вблизи анода по сравнению с таковой вблизи катода по следующим формулам:

$$
\begin{gathered}
\Delta_{C}=\frac{C(V)-C_{0}}{C_{0}} \cdot 100 \%, \\
\Delta_{C}^{ \pm}=\frac{C\left(V^{-}\right)-C\left(V^{+}\right)}{C\left(V^{+}\right)} \cdot 100 \%,
\end{gathered}
$$

где $C(V)-$ степень покрытия поверхности частицами, адсорбированными при приложении электрического поля: вблизи отрицательного $\left(C\left(V^{-}\right)\right)$или положительного $\left(C\left(V^{+}\right)\right)$контактов, $C_{0}-$ степень покрытия поверхности без приложения электрического поля.

На рис. 2 приведены зависимости $\Delta_{C}$ и $\Delta_{C}^{ \pm}$от напряженности поля. Из представленных на рис. 2, $a$ данных видно, что приложение вдоль поверхности подложки „тянущего“ электрического поля с малой напряженностью снижает адсорбцию микрокапсул как вблизи анода, так и вблизи катода. Однако увеличение напряженности поля приводит к росту числа адсорбированных микрокапсул. Так, при используемых в эксперименте полях число микрокапсул вблизи катода возрастало более чем в 2 раза (по сравнению с адсорбцией без приложения поля). Снижение адсорбции при малых напряженностях можно объяснить явлением электрофореза, т.е. перемещением частиц в электрическом поле, что затрудняет их адсорбцию. Поскольку микрокапсулы заряжены положительно, они движутся в направлении отрицательного контакта, увеличивая там свою концентрацию. Это должно приводить к росту количества адсорбированных микрокапсул вблизи отрицательного контакта за время адсорбции, что и наблюдается для $\Delta_{C}^{ \pm}$на рис. $2, b$. Разница достигает более $100 \%$ для бессолевой суспензии, т.е. абсолютная разница в количестве адсорбированных микрокапсул

Письма в ЖТФ, 2018, том 44, вып. 4 

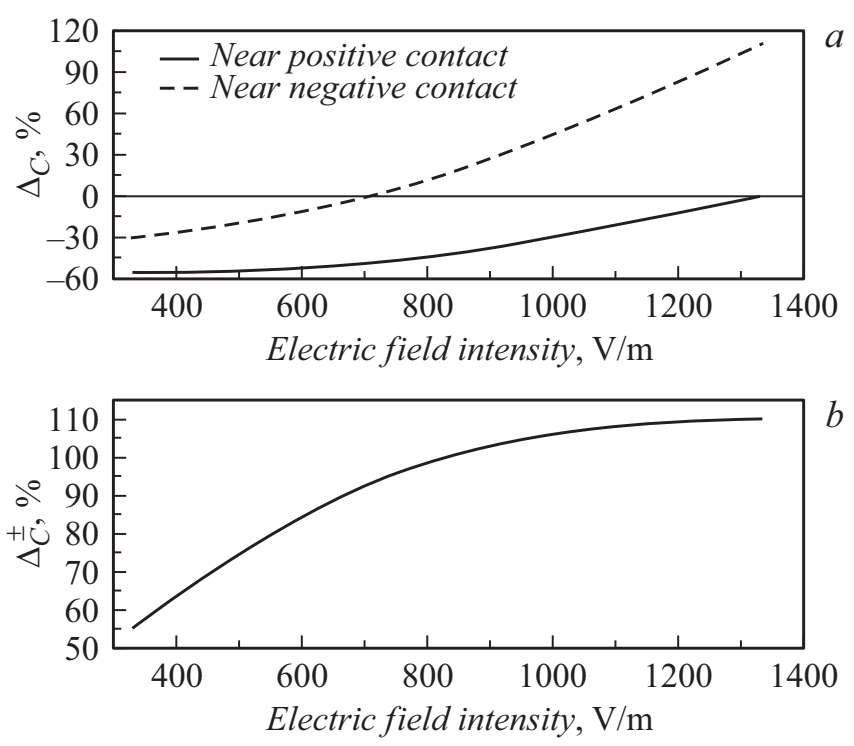

Рис. 2. Зависимости относительного изменения степени покрытия поверхности микрокапсулами $\Delta_{C}$ при приложении продольного электрического поля $(a)$ и относительное изменение степени покрытия вблизи отрицательного и положительного контактов $\Delta_{C}^{ \pm}(b)$ от напряженности электрического поля.

у положительного и отрицательного электродов различается более чем в 2 раза.

На рис. 3 представлена зависимость $\Delta_{C}^{ \pm}$от концентрации соли при напряженности поля $1.3 \mathrm{kV} / \mathrm{m}$. Добавление соли в раствор приводит к частичному экранированию заряда микрокапсул и как следствие к снижению числа адсорбированных частиц до $90 \%$ от значения в бессолевом растворе при малых концентрациях $\mathrm{NaCl}$ (до $0.2 \mathrm{M}$ ). При этом микрокапсулы адсорбируются преимущественно поштучно, не образуя скоплений, о чем свидетельствует снижение среднего размера адсорбированных частиц на $30 \%$ (до $1.4 \pm 0.1 \mu \mathrm{m}$ ). Значение $\Delta_{C}^{ \pm}$при этом снижается до 25\%. Дальнейшее увеличение концентрации $\mathrm{NaCl}$ (более $0.2 \mathrm{M}$ ) приводит к резкому росту $\Delta_{C}^{ \pm}$(до 8 раз от минимального значения). Такое поведение объясняется возникновением при больших напряженностях существенной разницы ионной силы раствора вблизи

Письма в ЖТФ, 2018, том 44, вып. 4 


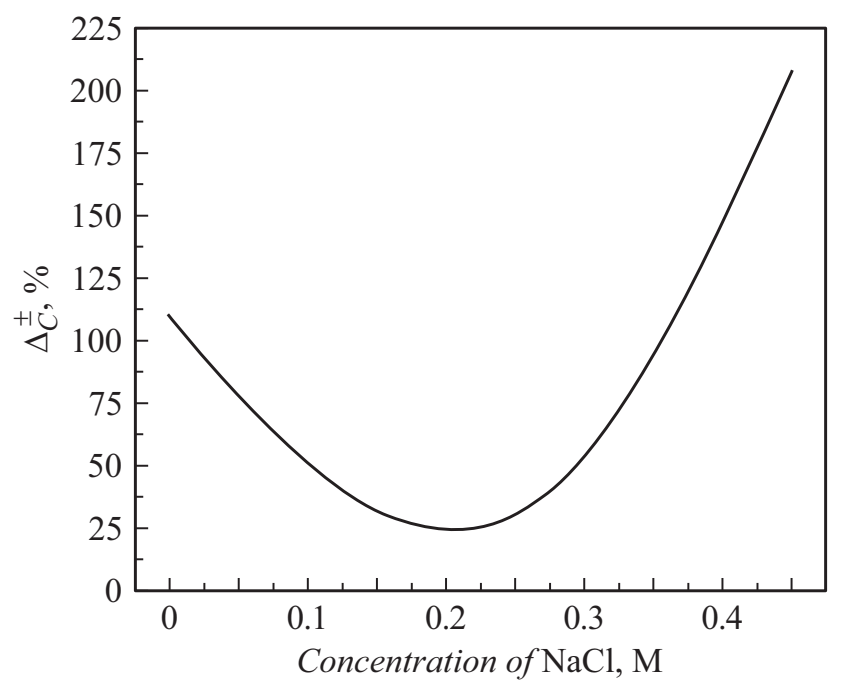

Рис. 3. Зависимость относительного изменения степени покрытия микрокапсулами $\Delta_{C}^{ \pm}$поверхности вблизи положительного и отрицательного контактов от концентрации $\mathrm{NaCl}$ в суспензии микрокапсул.

анода и катода, влияющей на заряд микрокапсул в растворе, а также может быть связано с ростом нанокристаллов соли вблизи катода при значительных степенях солености, которые могут служить центрами адсорбции.

Таким образом, можно заключить, что электрическое поле может быть использовано для управления адсорбцией микрокапсул: оно увеличивает количество адсорбированных микрокапсул с полезным грузом, например ферментами, и обеспечивает „селективность“ иммобилизации микрокапсул между положительными и отрицательными контактами. В перспективе возможно путем смены полярности напряжения при переносе подложки из одной суспензии в другую создавать монослойные мультиферментные покрытия из микрокапсул с одинаковой оболочкой и поверхностным зарядом, но с разной ферментной „начинкойс6.

Исследования выполнены при поддержке РФФИ (проект № 16-0800524_a).

Письма в ЖТФ, 2018, том 44, вып. 4 


\section{Список литературы}

[1] Монтрель М.М., Терновский В.И., Фомкина М.Г., Петров А.И. Патент РФ на изобретение № 2333231. Бюл. № 25. 2008.

[2] Zhang M.J., Wang W., Xie R., Ju X.J., Lui L., Gu Y.Y., Chu L.Y. // Soft Matter. 2013. V. 9. P. $4150-4159$.

[3] Sergeeva A.S., Gorin D.A., Volodkin D.V. // BioNanoScience. 2014. V. 4. P. 1-14.

[4] Маляр И.В., Santer S., Стецюра С.В. // Письма в ЖТФ. 2013. Т. 39. В. 14. C. 69-76.

[5] Malyar I.V., Gorin D.A., Santer S., Stetsyura S.V. // Appl. Phys. Lett. 2017. V. 110. P. 133104.

[6] Ko Y.H., Kim Y.H., Park J., Nam K.T., Park J.H., Yoo P.J. // Macromolecules. 2011. V. 44. P. 2866-2872.

[7] Стецюра С.В., Буланов М.С., Козловский А.В., Маляр И.В. // Нано- и микросистемная техника. 2017. № 2. C. 85-92.

[8] Sukhorukov G.B., Volodkin D.V., Günther A.M., Petrov A.I., Shenoy D.B., Möhwald H. // J. Mater. Chem. 2004. V. 14. P. 2073-2081. 